\title{
A Comparative Study to Evaluate Efficacy of Curcumin and Aloe Vera Gel along with Oral Physiotherapy in the Management of Oral Submucous Fibrosis: A Randomized Clinical Trial
}

\author{
Ashwini Nerkar Rajbhoj ${ }^{1 *}$, Tejas Mukund Kulkarni', Anagha Shete ${ }^{3}$, Mrinal \\ Shete $^{4}$, Rucha Gore ${ }^{4}$, Rashmi Sapkal ${ }^{5}$
}

\begin{abstract}
Rationale (Hypothesis): The antioxidant,anti-inflammatory,immunomodulatory and anti-tumorigenic properties of natural plant's extracts like aloe Vera and curcumin may produce beneficial therapeutic effects on OSMF patients and may lead to their symptomatic relief. Also, increase in the tissue elasticity with the help of oral physiotherapy excercises, would help in reinforcing increment in mouth opening. Aim: The aim of the study is to compare the efficacy of Curcumin gel with Aloe Vera gel when both the gel are supplemented along with oral physiotherapy in the management of OSMF. Materials and methods: A study of parallel group trial design, using simple randomization technique, was conducted on confirmed cases of OSMF. Patients were divided into two groups, one group(30 patients) was given curcumin gel(Curenext) and other group (30 patients) aloe Vera gel (Aloe Vera 100\% relief) and each group was asked to do same oral physiotherapy excercises supplementally. Follow-up was done for 6 weeks and patients were assessed on the basis of improvement in mouth opening and burning sensation at 2, 4, and 6 weeks. Results: There was an improvement in both the parameters at subsequent visits, but the Aloe Vera gel showed better improvement than curcumin gel in burning sensation after 6 weeks of treatment which was highly statistically significant $\mathrm{p}<0.01$. Conclusion: Curcumin gel and Aloe Vera gel are effective in improving OSMF symptoms, but aloe Vera gel is more efficacious in burning sensation improvement without any side effects. Hence, we can advocate these drugs as adjuvant treatment in addition to the recommended treatment.
\end{abstract}

Keywords: Aloe Vera- curcumin- oral submucous fibrosis- oral physiotherapy

Asian Pac J Cancer Prev, 22, Anticancer Activity of Natural Compounds: HOW's on Methods and Reports Suppl, 107-112

\section{Introduction}

Oral Sub mucous Fibrosis (OSMF) is defined as an insidious, chronic disease that affects any part of the oral cavity and sometimes the pharynx (Pindborg and Sirsat, 1966). Although, occasionally preceded by or/and associated with,the formation of vesicles, it is always associated with a juxta-epithelial inflammatory reaction followed by fibroelastic change of the lamina propria and epithelial atrophy that leads to stiffness of the oral mucosa causing trismus and inability to eat (Pindborg and Sirsat, 1966). Plants have been a major source of medicine since the time immemorial (Lai et al., 1995). It has been documented in the literature that many incurable oral diseases when treated with alternative medicine therapy such as Ayurveda have shown good prognosis (Lai et al., 1995). Aloe Vera is one such Ayurvedic treatment drug for OSMF (Sudarshan et al., 2012a). The polysaccharides that are present in the Aloe Vera leaves have wound healing, anti-inflammatory, anticancer, immunomodulatory as well as gastro-protective properties. It is also found to have soothing and cooling properties (Sudarshan et al., 2012a).

Aloe Vera plant is a rich source of antioxidants such as vitamins $\mathrm{A}, \mathrm{C}$ and $\mathrm{E}$ along with minerals, beta carotene, zinc, iron and selenium (Sudarshan et al., 2012a). Therefore, being a soothing, simple and safe mode of treatment when supplemented with strict restrictionon habits, it can be considered as an effectual treatment protocol in the management of OSMF.4 Curcumin is another Ayurvedic drug which is used in the treatment

${ }^{I}$ Department of Oral Medicine and Radiology, DY Patil Dental School, Pune, India. ${ }^{2}$ Department of Oral Medicine and Radiology, SMBT Institute of Dental Science and Research, Nandi Hills, Dhamangaon, Igaturi, Nashik, India. ${ }^{3}$ Department of Oral Medicine and Radiology, DY Patil Dental School, Pune, India. ${ }^{4}$ Department of Oral Pathology, DY Patil Dental School, Pune, India. ${ }^{5}$ Department of Oral Medicine and Radiology, M.A.Rangoonwala College of Dental Science and Research Center, Pune, India. *For Correspondence: drashwini.nerkar@gmail.com 
of OSMF (Lai et al., 1995). It inhibits proliferation, disrupts the cell cycle, induces apoptosis, and decreases expression levels of type I and III collagen (Sudarshan et al., 2012a). In patients who are presented with OSMF condition, curcumin significantly reduces expression of connective tissue growth factor associated with the onset and progression of OSMF (Rai et al., 2010; Zhang et al., 2012). Although OSMF is a clinical problem mostly managed by dental professionals, the question for improving elasticity an thus increasing mouth opening is prevailing.(Rajendran,1994; Fedorowicz et al., 2008). Hence, the basic physiotherapy technique, which has proved its valid response on various clinical conditions, may prove effective in managing OSMF as well (Pindborg and Sirsat, 1966). Till date, many clinical and interventional studies have been published regarding various treatment modalities for OSMF. All of them seem to help one way or another. Yet, we need to be aware of the fact that many of these treatment modalities have not been universally standardized. As a result, treatment of OSMF remains an enigma (Rajendran, 1994). Hence, the search for an effective treatment modality still continues. 8

Thus, the present study was the first ever study designed to evaluate and compare the efficacy of topical application of curcumin gel and Aloe Vera gel along with oral physiotherapy in OSMF patients.

\section{Materials and Methods}

This parallel group, prospective study was conducted in the Department of Oral Medicine and Radiology of D.Y Patil Dental School, Lohegaon, Pune with prior approval from the Institutional Ethics Committee. Predicting clinical significant effect of $10 \%$ or more for 6 months duration, the survival rate considered for both the groups was $64 \%$ and $74 \%$ respectively. Significance of 0.05 and a power of $0.8,50-60$ was the range of sample size required for the present study. Hence, the study comprised of 60 clinically and histopathologically confirmed cases of OSMF. Patients were included in the study after receiving positive response to informed consent. The age range of the selected patients was 15-55 years.

Based on inter-incisal distance, the patients were classified as given by Lai DR 2:

Group A/ Stage 1: Mouth opening greater than $35 \mathrm{~mm}$

Group B/ Stage 2: Mouth opening greater than 30 to $35 \mathrm{~mm}$ $30 \mathrm{~mm}$

Group C/ Stage 3: Mouth opening greater than 20 to

GroupD/ Stage 4: Mouth opening less than $20 \mathrm{~mm}$

\begin{tabular}{lcc}
\hline StagesOF OSMF & \multicolumn{2}{c}{ Number of Patients } \\
Group A & Group B \\
Total $=30$ & Total $=30$ \\
\hline 1 & 06 & 09 \\
2 & 11 & 09 \\
3 & 12 & 11 \\
4 & 01 & 01 \\
\hline
\end{tabular}

The groups were allotted to the patients using simple randomization method.

\section{Inclusion Criteria}

1) Patients diagnosed clinically and histopathologically for OSMF

2) Patients without any treatment for last 3-4months for OSMF

3) Patients ready for regular follow-up

4) Patients those who were willing to quit habits.

\section{Exclusion Criteria}

1) Patients hypersensitive to Aloe Vera

2) Patients hypersensitive to curcumin

3) Patients suffering from psychiatric disorder

4) Patients with any TMJ dysfunction

5) OSMF patients with malignant transformation.

\section{Procedure}

A detailed history of patients was recorded regarding chief complaint along with the habit history. The intensity of burning sensation was determined using a numerical rating Visual Analogue Scale (VAS) and was graded on a 10 point scale from 0 to 10 , where Orepresented no burning sensation while 10 represented the worst burning sensation possible.The inter-incisal distance i.e.mouth opening was measured using a vernier caliper from the mesio-incisal angle of upper central incisor to the mesio-incisal angle of lower central incisor and was recorded in millimeters.

Group A included 30 patients with OSMF who received curcumin gel (Curenext oral gel) along with physiotherapy. In a custom-made single plastic container, individual patient was given $5 \mathrm{mg}$ of gel separately. Altogether $1 \mathrm{gm}$ of gel was given to each patient at every visit. Detailed procedure about placement of cotton rolls and application of curcumin gel was explained to the patients. The patients were told to apply $5 \mathrm{mg}$ of gel at respective site for 3-4 times a day on either side, so that every day total $5 \mathrm{mg}$ of gel would be applied. Precautions such as avoidance of spitting saliva and no intake of any foodor liquid for atleast 15-20 minutes post topical application were advised. Same procedure was repeated with Group B receiving Aloe Vera gel (aloe gel 100\%). For forceful mouth opening oral physiotherapy exercises such as ice cream stick exercise, 5 times a day was advised. Every time patient was recalled, parameters such as mouth opening in $\mathrm{mm}$ and burning sensation on VAS were recorded. All the findings were tabulated in a Microsoft Excel sheet and then subjected to statistical analysis.

\section{Results}

In light of the objectives of the study to compare the burning sensation and mouth opening between both the groups' i.e. curcumin with oral physiotherapy and Aloe Vera with oral physiotherapy and to find out whether there is statistically significant difference among them, Unpaired Student's t-test was used. The Paired Student's t-test was used to compare burning sensation and mouth opening individually within each group and for the change in the staging of OSMF in both the groups (A and B), pre and post treatment. Level of significance was judged by $\mathrm{p}$ value. For statistical significance, $\mathrm{p}$ value $<0.05$ was considered. 
Table 1. Burning Sensation Score (vas) in Group A (Curcumin with Oral Physiotherapy)

\begin{tabular}{lccc}
\hline Sittings & mean $\pm \mathrm{sd}$ & $\begin{array}{c}\text { mean difference } \\
\text { (baseline } \\
\text { consecutive sittings) }\end{array}$ & $\mathrm{p}$ value \\
\hline Baseline & $7.500 \pm 1.548$ & - & - \\
$1^{\text {st }}$ visit & $6.533 \pm 1.570$ & $0.9667 \pm 0.4138$ & $<0.05^{*}$ \\
$2^{\text {nd }}$ visit & $6.033 \pm 1.829$ & $1.467 \pm 0.6288$ & $<0.01^{* *}$ \\
$3^{\text {rd }}$ visit & $5.133 \pm 1.795$ & $2.367 \pm 0.7184$ & $<0.01^{* *}$ \\
$4^{\text {th }}$ visit & $4.433 \pm 1.813$ & $3.06 \pm 0.944$ & $<0.01^{* *}$ \\
\hline
\end{tabular}

Table 2. Burning Sensation Score (vas) in Group b (Aloe Vera with Oral Physiotherapy)

\begin{tabular}{lccc}
\hline Sittings & mean $\pm \mathrm{sd}$ & $\begin{array}{c}\text { mean difference } \\
\text { (baseline } \\
\text { consecutive sittings) }\end{array}$ & p value \\
\hline Baseline & $7.333 \pm 1.470$ & - & - \\
$1^{\text {st }}$ visit & $6.100 \pm 1.539$ & $1.233 \pm 0.4302$ & $<0.01 * *$ \\
$2^{\text {nd }}$ visit & $5.033 \pm 1.650$ & $2.300 \pm 0.8367$ & $<0.01^{* *}$ \\
$3^{\text {rd }}$ visit & $3.867 \pm 1.548$ & $3.467 \pm 0.9732$ & $<0.01 * *$ \\
$4^{\text {th }}$ visit & $2.833 \pm 1.663$ & $4.500 \pm 1.106$ & $<0.01 * *$ \\
\hline
\end{tabular}

\section{Age Distribution}

Group A and B were comprised of patients with the age range of 15-55 years. Age mean value for group $A$ and group B was 29.4 and 31.2 years respectively.

\section{Gender Distribution}

Group A consisted of $6.66 \%$ females and $93.3 \%$ males. Group B consisted of $10 \%$ females and $90 \%$ males.

\section{Distribution of Forms of Habit}

The highest $\%$ of form of habit was Gutka $41.66 \%$ and the least was plain pan masala $3.33 \%$.

\section{Distribution of Duration of Habit}

Among 60 patients from both the groups, the highest $\%$ of duration of habit was up to 4-6 years in almost 55\% of patients. Least duration was up to 11-15 years or more

Table 3. The Inter- and Intragroup Comparison of Burning Sensation Score in each Study Group

\begin{tabular}{|c|c|c|c|}
\hline $\begin{array}{l}\text { Burning } \\
\text { Sensation }\end{array}$ & $\begin{array}{c}\text { Group A } \\
\text { (Curcumin } \\
\text { Gel With } \\
\text { Physiotherapy) }\end{array}$ & $\begin{array}{c}\text { Group A } \\
\text { (Aloevera } \\
\text { Gel With } \\
\text { Physiotherapy) }\end{array}$ & P-value \\
\hline Baseline & $7.500 \pm 1.548$ & $7.333 \pm 1.470$ & $>0.05$ \\
\hline $1^{\text {st }}$ Visit & $6.533 \pm 1.570$ & $6.100 \pm 1.539$ & $>0.05$ \\
\hline $2^{\text {nd }}$ Visit & $6.033 \pm 1.829$ & $5.033 \pm 1.650$ & $<0.05$ \\
\hline $3^{\text {rd }}$ Visit & $5.133 \pm 1.795$ & $3.867 \pm 1.548$ & $<0.01$ \\
\hline $4^{\text {th }}$ Visit & $4.433 \pm 1.813$ & $2.833 \pm 1.663$ & $<0.01$ \\
\hline \multicolumn{4}{|c|}{ Intragroup Comparison } \\
\hline Pre Vs $1^{\text {st }}$ Visit & $0.9667 \pm 0.4138$ & $1.233 \pm 0.4302$ & \\
\hline Pre Vs $2^{\text {nd }}$ Visit & $1.467 \pm 0.6288$ & $2.300 \pm 0.8367$ & \\
\hline Pre Vs $3^{\text {rd }}$ Visit & $2.367 \pm 0.7184$ & $3.467 \pm 0.9732$ & \\
\hline Pre Vs $4^{\text {th }}$ visit & $3.06 \pm 0.944$ & $4.500 \pm 1.106$ & \\
\hline
\end{tabular}

Table 4. Mouth Opening Score (in $\mathrm{mm}$ ) in Group A (Curcumin with Oral Physiotherapy)

\begin{tabular}{lccc}
\hline Sittings & mean \pm sd & $\begin{array}{c}\text { mean difference } \\
\text { (baseline } \\
\text { consecutive sittings) }\end{array}$ & p value \\
\hline Baseline & $30.5 \pm 6.301$ & - & - \\
$1^{\text {st }}$ visit & $30.5 \pm 6.301$ & $0.00 \pm 0.00$ & $>0.05$ \\
$2^{\text {nd }}$ visit & $30.86 \pm 6.268$ & $0.367 \pm 0.7184$ & $>0.05$ \\
$3^{\text {rd }}$ visit & $32.0 \pm 6.231$ & $1.50 \pm 0.9377$ & $>0.05$ \\
$4^{\text {th }}$ visit & $32.23 \pm 6.25$ & $1.733 \pm 1.048$ & $>0.05$ \\
\hline
\end{tabular}

Table 5. Mouth Opening Score (in $\mathrm{mm}$ ) in Group B (Aloe Vera with Oral Physiotherapy)

\begin{tabular}{lccc}
\hline Sittings & mean $\pm \mathrm{sd}$ & $\begin{array}{c}\text { mean difference } \\
\text { (baseline } \\
\text { consecutive sittings) }\end{array}$ & $\mathrm{p}$ value \\
\hline Baseline & $31.500 \pm 6.740$ & - & - \\
$1^{\text {st }}$ visit & $31.533 \pm 6.709$ & $0.033 \pm 0.1826$ & $>0.05$ \\
$2^{\text {nd }}$ visit & $31.833 \pm 6.711$ & $0.333 \pm 0.6065$ & $>0.05$ \\
$3^{\text {rd }}$ visit & $32.600 \pm 6.652$ & $1.100 \pm 0.8449$ & $>0.05$ \\
$4^{\text {th }}$ visit & $32.867 \pm 6.663$ & $1.367 \pm 1.129$ & $>0.05$ \\
\hline
\end{tabular}

than 15 years in $3.33 \%$ of patients.

\section{Burning Sensationt}

In both the groups, reduction in burning sensation was observed at every consecutive visit when compared with the baseline score (Table 1). Using paired t-test, the difference showed statistical significance with $\mathrm{p}$ value $<0.05$ individually (Table 2 ). However, the mean difference between the baseline and consecutive sittings was observed more in Group B (Aloe Vera) than in Group A (curcumin). Using unpaired t-test, the difference showed statistical significance and $\mathrm{p}$ value $<0.05$ (Table 3 ).

\section{Mouth Opening}

Increase in average mouth opening was observed at every consecutive visit when compared with the baseline score for both the groups (Table 4). Using paired t-test,

Table 6. The Inter- and Intragroup Comparison of Mouth Opening (in $\mathrm{mm}$ ) in each Study Group

\begin{tabular}{lccc}
\hline Mouth Opening & $\begin{array}{c}\text { Group A } \\
\text { (Curcumin } \\
\text { Gel With } \\
\text { Physiotherapy) }\end{array}$ & $\begin{array}{c}\text { Group A } \\
\text { (Aloevera } \\
\text { Gel With } \\
\text { Physiotherapy) }\end{array}$ & P-Value \\
\hline Baseline & $30.5 \pm 6.301$ & $31.500 \pm 6.740$ & $>0.05$ \\
1st Visit & $30.5 \pm 6.301$ & $31.533 \pm 6.709$ & $>0.05$ \\
2nd Visit & $30.86 \pm 6.268$ & $31.833 \pm 6.711$ & $>0.05$ \\
3rd Visit & $32.0 \pm 6.231$ & $32.600 \pm 6.652$ & $>0.05$ \\
4th Visit & $32.23 \pm 6.25$ & $32.867 \pm 6.663$ & $>0.05$ \\
Intragroup Comparison & $0.00 \pm 0.00$ & $0.033 \pm 0.1826$ & $>0.05$ \\
Pre Vs $1^{\text {st }}$ Visit & $0.367 \pm 0.7184$ & $0.333 \pm 0.6065$ & $>0.05$ \\
Pre Vs $2^{\text {nd }}$ Visit & $1.50 \pm 0.9377$ & $1.100 \pm 0.8449$ & $>0.05$ \\
Pre Vs $3^{\text {rd }}$ Visit & $1.733 \pm 1.048$ & $1.367 \pm 1.129$ & $>0.05$ \\
\hline Pre Vs $4^{\text {th }}$ Visit & & & \\
\hline
\end{tabular}

Asian Pacific Journal of Cancer Prevention, Vol 22 
Table 7. Comparison between Group A and Group B on the Basis of Stages of OSMF Pre and Post Treatment

\begin{tabular}{|c|c|c|c|c|c|c|c|c|c|c|}
\hline \multirow{3}{*}{$\begin{array}{l}\text { Stages of OSMF } \\
\text { Grades }\end{array}$} & \multicolumn{5}{|c|}{ Group A } & \multicolumn{5}{|c|}{ Group B } \\
\hline & \multicolumn{2}{|c|}{ Pre-treatment } & \multicolumn{2}{|c|}{ Post-treatment } & \multirow[t]{2}{*}{ p-value } & \multicolumn{2}{|c|}{ Pre-treatment } & \multicolumn{2}{|c|}{ Post-treatment } & \multirow[t]{2}{*}{$\mathrm{p}$-value } \\
\hline & no. & $\mathrm{n}(\%)$ & no. & $\mathrm{n}(\%)$ & & no. & $\mathrm{n}(\%)$ & no. & $\mathrm{n}(\%)$ & \\
\hline 1 & 6 & 35.29 & 11 & 64.70 & 0.05 & 9 & 40.90 & 13 & 59.09 & 0.05 \\
\hline 2 & 11 & 55.00 & 9 & 45.00 & 0.07 & 9 & 52.94 & 8 & 47.05 & 0.07 \\
\hline 3 & 12 & 57.14 & 9 & 42.85 & 0.06 & 11 & 57.89 & 8 & 42.10 & 0.06 \\
\hline 4 & 1 & 50.00 & 1 & 50.00 & - & 1 & 50.00 & 1 & 50.00 & - \\
\hline
\end{tabular}

the difference found was statistically insignificant with $\mathrm{p}$ value $>0.05$ individually (Table 5). However, the mean difference between the baseline and consecutive sittings was observed more in Group A (Curcumin) than in Group B (Aloe Vera). Using unpaired t-test, the difference showed statistical insignificance with $\mathrm{p}$ value $>0.05$ (Table 6).

\section{Stages of OSMF}

Pre and post treatment, change in the number of patients for each stage of OSMF patients (except stage 4) was observed. Post treatment, Group A showed 11 patients in stage 1 and group B showed 13 patients in stage 1 . Using paired $t$ test, the mean difference observed among change of number of patients for each stage of OSMF, pre and post treatment was statistically insignificant with $\mathrm{p}$ value $>0.05$ (Table 7).

\section{Discussion}

It is a known fact that once OSMF has developed, there is neither total regression nor any effective treatment till date (Rajendran, 1994). Treatment of OSMF stated by Cochrane review suggests that, the paucity of data and poor methodological quality of studies indicate a lack of reliable evidence for the effectiveness of any specific intervention for the management of this disease (Fedorowicz et al., 2008). Aloe Vera is widely used for its medicinal properties. It has been studied for the treatment of oral mucosal conditions such as major Apthous ulcer10, lichen planus11, burning mouth syndrome12 and OSMF. (Sudarshan et al., 2012a; Alam et al., 2013; Patil et al., 2014; Patil et al., 2015a; Patil et al., 2015b). Another treatment modality which is gaining recognition, is the use of curcumin in OSMF. Curcumin is the principal curcuminoid found in turmeric and comprises of approximately 2-5\% of turmeric (Lawande, 2013). AGE: In the present study, the mean age reported was 29.43 years and 31.2 years in Group A and B respectively, which was in accordance with the mean age found in other studies (Sudarshan et al., 2012a; Patil et al., 2015b).

This age range, predominance could be seen, may be because of this age range of people to be the highest range having addiction such as tobacco chewing, gutka chewing, Areca nut chewing, Pan masala chewing etc. (Sudarshan et al., 2012a; Sudarshan et al., 2012b; Rajendran, 1994; Patil et al., 2015b). GENDER: In present study, the gender distribution was such that, there were 28 males and 02 females in Group A and 27 males and 03 females in Group B. This male ascendancy was in accordance with other studies.3.13 This could be due to possibility of easier access to abusive habits or less social restrictions for males as compared to females (Alam et al., 2013; Patil et al., 2014; Patil et al., 2015a; Patil et al., 2015b).

\section{Burning Sensation}

In the present study, both the groups, Group A and B showed statistically significant reduction in burning sensation from baseline up to the last visit. The inference states that the reduction was more in Group B (Aloe Vera along with oral physiotherapy) as compared to Group A (curcumin along with oral physiotherapy) and the difference was statistically significant (Table 3 ). These results were in accordance with the study by Sudharshan et al conducted in 2012. The reduction in burning sensation can be due to peculiar anti-inflammatory properties of Aloe Vera. The probable mechanisms for the antiinflammatory action of Aloe Vera are as follows:

1. Carboxypeptidase in aloe inactivates bradykinin which is a principle participant of inflammation (Fujita et al., 1975).

2. Magnesium lactate present in Aloe Vera inhibits histidine decarboxylase, thereby preventing the formation of histamine in mast cells (Fujita et al., 1975).

3. Salicylates are by-products of amodin, aloe-emodin and aloin (Klein et al., 1980).

4. Peptidasebradykinin isolated from Aloe Vera breaks down bradykinin, an inflammatory substance that induces pain (Klein et al., 1980).

5. Reduction in leukocyte adhesion and TNF- $\alpha$ level results in inhibition of inflammatory process (Robson et al., 1982).

There are few studies which have concluded stating, significant reduction in burning sensation score with the use of curcumin when used in different forms such as oil, lozenges, capsules etc., but not in the gel form and in comparison to treatment modalities other than Aloe Vera gel. A study conducted by Yadav et al., (2014) compared curcumin with intralesional steroid injections in OSMF patients and found complete resolution of burning sensation in curcumin group as compared to that of intralesional group and the difference was statistically significant. A study conducted by Das et al., (2010) compared curcumin, turmeric oil and multinal tablets. The results stated statistically significant reduction in 
burning sensation in curcumin and turmeric oil group as compared to that of multinal tablets group. Amongst curcumin and turmeric oil, rapid reduction was seen in curcumin. Hararry et al., (2015) compared curcumin lozenges with clobetasol propionate and found statistically significant reduction in burning sensation score up to 3 months follow-up in curcumin group.

\section{Curcumin modulates the inflammatory response by:}

1. Down-regulating the activity of cyclooxygenase- 2 (COX-2), lipoxygenase and inducible nitric oxide synthase (iNOS) enzymes (Julie and Jurenka, 2009).

2. Inhibits the production of the inflammatory cytokines, tumor necrosis factor-alpha (TNF-alpha), interleukin (IL) 1, 2,6,8, and 12, Monocyte Chemo-attractant Protein (MCP), and migration inhibitory protein (Tuba and Gulcin, 2008).

According to the results of present study, burning sensation score was found to improve more in Aloe Vera group as compared to curcumin. This may be due to the difference in the potency of their anti-inflammatory properties. There are published studies which indicate poor absorption of curcumin leading to low systemic availability. The systemic availability can be improved by curcumin-phospholipid complex as curcumin is lipid soluble (Julie and Jurenka, 2009; Tuba and Gulcin, 2008).

Also it has been stated that the same dose of different formulations may give rise to different mean serum curcumin concentrations and the reason being unclear. (Tuba and Gulcin, 2008).

Thus, the observations suggest that many questions such as difference in their potency of anti-inflammatory properties, addition of which drug supplement with them individually can increase their bioavailability, ideal formulations and dosages etc. remain unanswered.

\section{Mouth Opening}

In the present study, both the groups showed increase in mouth opening from baseline to the last visit. The inference states that the increase was found to be more in Group A as compared to Group B, but the difference was statistically non-significant (Table 6). These results are in accordance with the study of by Pratik et al., (2016). The study results stated that, the improvement in mouth opening in turmeric with black pepper and nigella silver group could be seen but the difference was statistically nonsignificant. Hazzarey et al., (2015) compared curcumin lozenges with clobetasol propionate and found statistically significant increase in mouth opening. Raiet al., (2010) reported that in patients with submucous fibrosis, mouth opening restored significantly $(\mathrm{p}<0.05)$ after 6 months of the treatment. Patil et al in 2014 and two other studies in 2015 compared oxitard, lycopene and spirulina with Aloe Vera gel respectively. The results of all three studies stated statistically significant improvement in mouth opening in oxitard, lycopene and spirulina group respectively as compared to Aloe Vera gel. Curcumin is regarded as fibrinolytic agent in chinese medicine (Kuttan et al., 1987; Chang and But, 1987; Li et al., 1993). attributed the fibrinolytic action of curcumin to its three properties namely inhibition of lipid peroxidation, checking cellular proliferation and inhibition of collagen synthesis. Few studies have suggested an increase in fibroblast activities resulting in increased collagen content on application of Aloe Vera gel (Davis et al., 1991; Heggers et al., 1995; Williams et al., 1996; El Khoury et al., 2015).

In the present study, all the patients of both the groups have shown significant improvement in clinical parameters irrespective of Clinical staging. For both the groups, overall response was better in patients with stage 2 and 3 OSMF (Table 7). Overall correlation with the treatment outcome was not possible because of the unequal distribution of patients belonging to different stages.

In conclusion, curcumin and Aloe Vera both can be considered as safe, non-toxic and effective alternatives for many conventional drugs in treating patients with OSMF irrespective of its clinical stage.

\section{Acknowledgments}

\section{Abbreviations}

OSMF - Oral submucous fibrosis, DVC-Digital vernier caliper, VAS-Visual analog scale, BS-Burning sensation, MO-Mouth opening, PRE-Pretreatment, POS-post treatment.

\section{Limitations}

The follow-up was for shorter duration. In the present study, the sample size was small and there was an unequal distribution of the patients among different clinical stages.

\section{Scope for future work}

Studies involving equal distribution of the cases among all the clinical stages, with larger sample size, longer follow-up period can be considered. It will thus help in deciding a definitive and noninvasive treatment option for OSMF patients.

\section{Statement conflict of Interest}

No conflict of interest.

\section{References}

Alam S, Ali I, Giri K, G et al (2013). Efficacy of aloe vera gel as an adjuvant treatment of oral submucous fibrosis. Oral Surg Oral Med Oral Pathol Oral Radiol, 116, 717-24.

Chang H, But PP (1987). Pharmacology and applications of chinesemateriamedica-2, World Scientific Publishing Company, Singapore, 34, pp 28-30

Choonhakarn C, Busaracome P, Sripanidkulchai B, Sarakarn P (2008). The efficacy of aloe vera gel in the treatment of oral lichen planus a randomized controlled trial. Br J Dermatol, 158, 573-7.

Davis RH, Parker WL, Samson RT, Murdoch DP (1991). Isolation of a stimulatory system in an aloe extract. $\mathrm{J} \mathrm{Am}$ Podiatr Med Assoc, 81, 473-8.

El Khoury E, Abiad M, Kassaify ZG, Patra D (2015). Green synthesis of curcumin conjugated nano silver for the applications in nucleic acid sensing and anti-bacterial activity. Colloids Surf B Biointerfaces, 7, 274-80.

Fedorowicz Z, Chan Shih-Yen E, Dorri M, et al (2008). Interventions for the management of oral submucous fibrosis Asian Pacific Journal of Cancer Prevention, Vol 22 
(Review). Cochrane Libr, 4, 1-17.

Fujita K, Teradaira R (1976). Bradykininase activity of Aloe extract. Biochem Pharmacol, 25, 205-10.

Garnick JJ, Singh B, Winkley G (1998). Effectiveness of a medicament containing silicon dioxide, aloe, and allantoin on aphthous stomatitis. Oral Surg Oral Med Oral Pathol Oral Radiol Endod, 86, 550-600.

Heggers JP, Kucukcelibi A, Stabenou CJ, et al (1995). Wound healing effects of the aloe gel and other topical antibacterial agents in rat skin. Phytother Res, 9, 455-7.

Julie S, Jurenka MT (2009). Anti-inflammatory properties of curcumin, a major constituent. Alternative Med Rev, 2, 14-9.

Klein AD (1980). Aloe-Vera. J Am Acad Dermatol, 18, 714-20.

Kuttan R, Sudheeran PC, Josph CD (1987). Turmeric and curcumin as topical agents in cancer therapy. Tumori, 73, 29-31.

Lai DR, Chen HR, Lin LM, Huang YL, Tsai CC (1995). Clinical evaluation of different treatment methods for oral submucous fibrosis -A 10-year experience with 150 cases. J Oral Pathol Med, 24, 402-659.

Lawande SA (2013). therapeutic applications of turmeric (curcuma longa) in dentistry: a promising future. J Pharm Biomed Sci, 27, 586-91.

LI CJ, Zhang LJ, Dezube BJ, Crumpacker CS, Pardee AB (1993). Three inhibitors of type I human immunodeficiency virus long terminal repeat direct gene expression and virus replication. Proc Natl Acad Sci U S A, 90, 1839-42.

Lopez-Jornet P, Camacho-Alonso F, Molino-Pagan D (2012). Prospective, randomized, double-blind, clinical evaluation of Aloe vera,Barbadensis, applied in combination with a tongue protector to treat burning mouth syndrome. J Oral Pathol Med, 42, 295-301.

Patil S, Al-Zarea B, Maheshwari S, Sahu R (2015a). Comparative evaluation of natural antioxidants spirulina and aloe vera for the treatment of oral submucous fibrosis. J Oral Biol Craniofac Res, 5, 11-5.

Patil S, Halgatti V, Maheshwari S, Santosh B (2014). Comparative study of the efficacy of herbal antioxidants oxitard and aloe vera in the treatment of oral submucous fibrosis. J Clin Exp Dent, 6, 265-70.

Patil S, Sahu R, Sghaireen M, Kunsi S, Maheshwari S (2015b). Comparative study of the efficacy of lycopene and aloe verainthe treatment of oral submucous fibrosis. Int $J$ Health Allied Sci, 4, 13-8.

Pindborg JJ, Sirsat SM (1966). Oral submucous fibrosis. Oral Surg Oral Med Oral Pathol, 22, 764-94.

Rai B, Kaur J, Jacobs R, Singh J (2010). Possible action mechanism for curcumin in pre- cancerous lesions based on serum and salivary markers of oxidative stress. $J$ Oral Sci, 52, 251-6.

Rajendran R (1994). Oral submucous fibrosis: etiology, pathogenesis, and future research. Bull World Health Organ, 72, 985-96.

Robson MC, Heggers JP, Hagstrom WJ (1982). Myth, magic, witchcraft or fact? Aloe-Vera revisited. J Burn Care Rehabil, 3, 157-62.

Sudarshan R, Annigeri RG, Sree VG (2012a). Pathogenesis of oral submucous fibrosis: The past and current concept. Int J Oral Maxillofacial Pathol, 3, 27-36.

Sudarshan R, Annigeri RG, Vijayabala GS (2012b). Aloe vera in the treatment for oral submucous fibrosis - a preliminary study. J Oral Pathol Med, 41, 755-61.

Tuba AK, Gulcin I (2008). Antioxidant and radical scavenging properties of curcumin. Chem Biol Interact, 174, 21-31.

Williams MS, Burk M, Loprinzi CL, et al (1996). Phase III double-blind evaluation of an Aloe vera gel as a prophylactic agent for radiation-induced skin toxicity. Int J Radiat Oncol
Biol Phys, 36, 345-9.

Zhang SS (2012) Antifibrotic effect of curcumin in TGF-[25] $\beta 1$-induced myofibroblasts from human oral mucosa. Asian Pac J Cancer Prev, 13, 289-94.

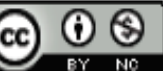

This work is licensed under a Creative Commons AttributionNon Commercial 4.0 International License. 